\title{
Reproductive Health Constraints in Dairy Cows Managed Under Smallholder Farms of East Shewa, Ethiopia
}

\author{
Markos Tadele \\ Ethiopian institute of agricultural research/EIAR \\ Ejegayehu Demisse \\ Ethiopian institute of agricultural researches \\ Beksisa Urge \\ Ethiopian institute of agricultural researches
}

\begin{abstract}
Reproduction is a basic requirement to increase stock size, successfully replace culled cows and maintain constant milk production in dairy farms. However, the reproductive physiology of dairy cows is disturbed by several factors, the most important of which are reproductive disorders. The current study was conducted to identify major reproductive health problems in two selected zones of Oromia National Regional State, Ethiopia. Reproduction and production performance history of selected cows were collected from 123 farm owners. The mean age, parity, age at first calving (AFC), age at first service (AFS), calving to first service (CFS), service per conception (SPC), average calving interval (ACI), the average lactation length and average daily milk yield were $65.8 \pm 30.5 \mathrm{M}, 2.48$ $\pm 1.6,30 \pm 8.6 \mathrm{M}, 19.61 \pm 6.3,3.3 \pm 1.7 \mathrm{M}, 2.75 \pm 1.74 \mathrm{M}, 14.3 \pm 3.4 \mathrm{M}, 11.5 \pm 3.4 \mathrm{M}$ and $12.3 \pm 6.6 \mathrm{~L}$, respectively. From a total of 252 studied dairy cows, $102(40.5 \%)$ had either a history or active reproductive health problem. Among the problems identified, mastitis (43.6\%), abortion (13.8\%), retention of placenta $(21.3 \%)$ and dystocia $(7.4 \%)$ were found with high magnitude. While Vaginal prolapses (1.6\%), repeated breeding $(3.25 \%)$ and anoestrus $(5.3 \%)$ were other reproductive health problems with a relatively lower incidence rate. Age $(\mathrm{p}=0.01)$, Breed $(p=0.04)$ and body condition $(p=0.04)$ were identified as risk factors for reproductive problem. The observed reproductive health problems were higher as compared to other reports. Therefore, the constraints need to be addressed using holistic interventions which consist of feeds and nutrition, breeding and health packages.
\end{abstract}

DOI: $10.7176 / \mathrm{JBAH} / 11-11-02$

Publication date:June $30^{\text {th }} 2021$

\section{Background and justification}

Reproduction is a basic prerequisite to efficient livestock production. The general reproductive aim of all dairy farms is to obtain a calf every year without an extended calving interval. This is very important to increase stock size, successfully replace culled cows and maintain constant milk production in the farm. The reproductive and milk production performance of indigenous dairy cattle is generally low. In an attempt to increase milk production, pure exotic breed dairy animals are being imported to the country and indigenous cattle performance is being improved through cross-breeding.

Ethiopia is a country with vast productive livestock resources comprising about 59 million cattle, out of which milking cows constitute to be around 12 million (CSA n.d.). The livestock sub-sector contributes an estimated $12 \%$ of the total and over $45 \%$ to the agricultural GDPs (CSA n.d.). Moreover, livestock serves as an important source of livelihood to over $60 \%$ of the national population. The benefit harnessed from the sector, however, is far below the potential. This is mainly due to poor management practices, poor nutrition, high disease incidence, and low genetic potential (Yalew, Lobago, and Goshu 2011).

Reproductive disorders and associated losses prevent successful breeding and milk production at farm level which in turn hinders dairy development in a country (Nakada 2006). These disorders can result from infectious and noninfectious causes. Abortion, dystocia, retention of the placenta (ROP), metritis, prolapse (uterine and vagina), anestrus and repeat breedings were reported as major conditions affecting dairy cows (Lobago et al. 2006; Shiferaw et al. 2005; Zemenu, Belete, and Ahmed 2018).

The above-mentioned disorders can also be emanated from the invasion of genital organs by pathogenic microorganism. The infectious causes of reproductive diseases in cattle so far reported in Ethiopia are viral: BVD, BHV, and IBR (Sibhat et al. 2018), bacterial: Brucella spp., Coaxella burnetii, Campylobacter fetus, Leptospira spp., and Listeria monocytogenes (Ibrahim 2018; Rashid n.d.; Town 2017; Zemenu et al. 2018), and protozoal: Toxoplasma gondii, Neospora caninum, Trichomonas fetus (Ibrahim 2018; Lema, Kassa, and Tegegne 2001). The current study was conducted to investigate the major reproductive constraints in two zones of the Oromia region. 


\section{Materials and methods}

2.1 Study Area

The study was conducted in two zones of the Oromia region, namely East Shewa and Oromia Finfine Special Zone Dukem City Administration (OFSZDCA).

\subsection{Study animals}

The study animals were local and crossbred dairy cattle reared in smallholder and commercial dairy farms located in and on the outskirts of major towns of the study areas.

\subsection{Study Design}

A cross-sectional study using a semi-structured questionnaire was conducted to investigate the major reproductive health problems in the area. The study was done by selecting dairy cows in representative farms. Clinical examination was performed at the spot and history on production and reproduction performance was taken from owners and from individual cow records, when possible, to determine the patterns, magnitude and causes of reproductive disorders.

\subsection{Sampling Approach}

Study zones, districts and peasant associations were selected using multi-stage random sampling procedure. Households and study animals were selected purposively. The selection criteria were ease of access and the presence of one or more dairy cows in the farm at the time of the study. All dairy cows in selected farms with or without a history of reproductive disorders were considered for the study.

\subsection{Study methods}

A semi-structured questionnaire was designed, tested in a pilot study and employed to collect information about livestock holding pattern, management practices, production and reproductive performance, existing constraints and the magnitude and clinical presentation of reproductive disorders. The clinical study was performed on selected animals at the time of investigation and cases were diagnosed tentatively.

Assessment of reproductive disorders from all the study animals, information concerning herd size, age, breed, parity, and history of reproductive disorders were recorded using the specific format prepared for the evaluation. Diagnosis of reproductive disorders was made based on history and observation of clinical sign of animals. The body condition score (BCS) of the animal was determined as 1,2,3,4 and 5 . Based on body condition score, animals were categorized into three groups; poor $(\mathrm{BCS}=1-2)$, medium $(\mathrm{BCS}=3)$ and good $(\mathrm{BCS}=4-5)$.

\subsection{Statistical analysis}

Data were collected using questionnaires, observational assessmnets and clinical inspections. The collected data was organized, cleared and coded using Ms Excel (2016) and transferred to SPSS and SAS for analysis. Descriptive statistics was performed using SPSS V20, results are presented as tables and figures. The interrelationship among reproductive disorders and association between production system and reproductive disorders was analysed with Bivariable and multivariable analysis using SAS 9.03. Variable having a p-value less than 0.05 in bivariate analysis were further analysed in multivariate analysis; a p-value of less than 0.05 in the final model were considered as statistically significant.

\section{Result and discussion}

A total of 123 dairy farms were selected for the study. Most of the respondents were male (52.8), and residents of East Shewa (48\%) and Oromia special zone (OSZSFDAC) (52\%). Most of the farms were intensive (84.4\%), while around $11.5 \%$ and $4.1 \%$ were managed by semi-intensive and extensive systems, respectively. The majority of the respondent $(91.8 \%)$ were smallholder farmers (Table 1$)$ 
Table 1: respondents' profile

\begin{tabular}{|l|l|l|l|}
\hline Question & Response category & Respondents No. & $\%$ \\
\hline Zone & East Shewa & 59 & 48 \\
\cline { 2 - 4 } & OFSZDCA & 64 & 52 \\
\hline \multirow{4}{*}{ Sex } & Male & 65 & 52.8 \\
\cline { 2 - 4 } & Female & 58 & 47.2 \\
\hline \multirow{5}{*}{ Farmagement system } & Intensive & 103 & 84.4 \\
\cline { 2 - 4 } & Extensive & 5 & 4.1 \\
\cline { 2 - 4 } & Semi intensive & 14 & 11.5 \\
\hline \multirow{5}{*}{ Years in dairy farming } & Private commercial & 8 & 6.6 \\
\cline { 2 - 4 } & Cooperative & 2 & 1.6 \\
\cline { 2 - 4 } & Small Holder & 112 & 91.8 \\
\hline & $1-15$ Years & 93 & 76.2 \\
\cline { 2 - 4 } & $15-30$ Years & 15 & 12.3 \\
\cline { 2 - 4 } & Above 30 Years & 14 & 11.5 \\
\hline
\end{tabular}

Most farms (84\%) raised their own stock; only $16 \%$ of the farms purchased dairy animals from other farms. About half of the farms (56\%) kept dairy cattle while the remaining farms (44\%) keep diverse species of animals. Crossbreed dairy cows were found to be dominant in farms (63.1\%) followed by exotic (27.9) and local (9) breed cows (Fig 1).

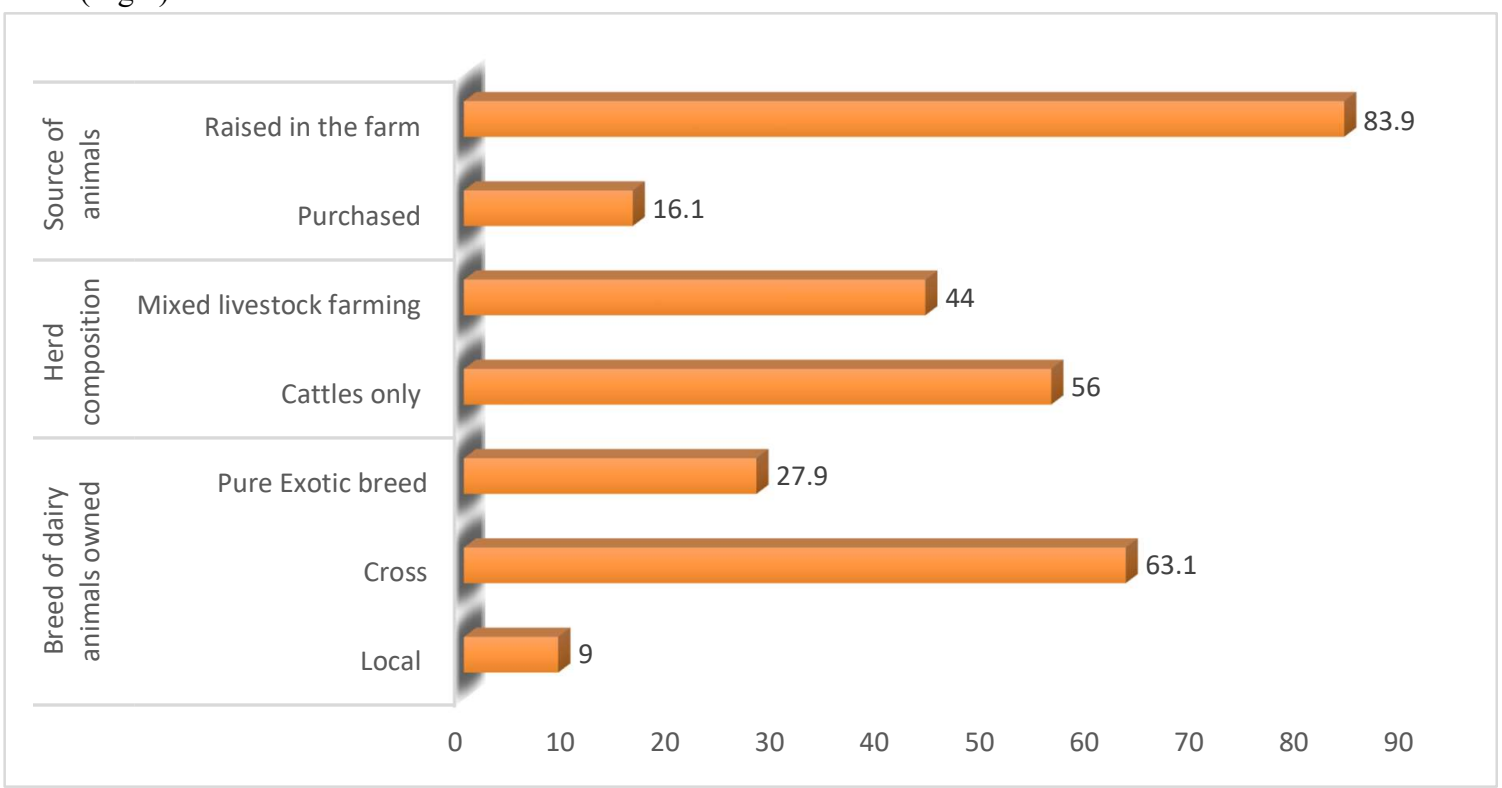

Figure 1: Livestock ownership and composition of selected farms

\subsection{Housing Condition}

A little more than half of the respondents keep their animals in a simple barn built adjacent to the living house (Table 3$)$. The roofs of the barns were covered by a corrugated iron sheet $(73.3 \%)$, hay $(2.6 \%)$ or plastic/rubbers (24.1\%). The walls were made of metal sheet (48.3\%), wood (26.3\%), plastic sheets $(16.9 \%)$ and mud $(6.4 \%)$. The floor system was mainly concrete $(70.7 \%)$ and mud and stone $(25 \%)$. Biosecurity measures were in place in only $15 \%$ of the farms. 
Table 2: housing condition of selected farms

\begin{tabular}{|l|l|l|l|}
\hline Question & Response category & Respondents No. & $\%$ \\
\hline \multirow{4}{*}{ Housing systems } & Simple Shed beside home & 63 & 52.5 \\
\cline { 2 - 4 } & Barn in separate compound & 57 & 47.5 \\
\hline \multirow{5}{*}{ Woof } & Iron sheet & 85 & 73.3 \\
\cline { 2 - 4 } & Grass & 3 & 2.6 \\
\cline { 2 - 4 } & Rubber and plastic & 28 & 24.1 \\
\hline & Iron sheet & 57 & 48.3 \\
\cline { 2 - 4 } & Woods only & 31 & 26.3 \\
\cline { 2 - 4 } & Blocks & 2 & 1.7 \\
\cline { 2 - 4 } & Plastic/Rubber & 20 & 16.9 \\
\cline { 2 - 4 } & Mud and Wood & 8 & 6.7 \\
\hline Floor & Concrete & 82 & 70.7 \\
\cline { 2 - 4 } & Soil & 29 & 25.0 \\
\cline { 2 - 4 } & Mud and Stone & 5 & 4.3 \\
\hline
\end{tabular}

\subsection{Reproductive performance of selected cows}

Data on reproductive and production performance was taken for 250 cows selected from 123 households. The average parity of selected cows was $2.48 \pm 1.6$ with the age range of $24-180$ months $(65.8 \pm 30.5)$. The AFS and the AFC of selected cows were $19.61 \pm 6.3$ and $30 \pm 8.6$, respectively. The average CFS, SPC, ACI, the average lactation length and average daily milk yield were $3.3 \pm 1.69$ months, $2.75 \pm 1.74$ months, $14.3 \pm 3.4$ months, 11.5 \pm 3.4 months and $12.3 \pm 6.6 \mathrm{~L}$, respectively. Calf mortality was reported in 75 farms; each farm on average losses 1.71 calves (Table 3 ).

Table 3: Means (months) of age at first service, Age at 1st caving, Calving to the first service, No. of services per conception and calving interval of cows managed under smallholder farms.

\begin{tabular}{|l|l|l|l|l|}
\hline Parameters & N & Mean \pm SD & Other reports & References \\
\hline Parity & 250 & $2.48 \pm 1.6$ & & \\
\hline Age (M) & 211 & $65.8 \pm 30.5$ & & \\
\hline AFS (M) & 189 & $19.61 \pm 6.3$ & $26-29 \mathrm{M}$ & (Shiferaw et al. 2003; Siyoum et al. 2016) \\
\hline AFC (M) & 196 & $30 \pm 8.6$ & $35-41 \mathrm{M}$ & $\begin{array}{l}\text { (Shiferaw et al. 2003; Siyoum et al. 2016; } \\
\text { Yalew et al. 2011) }\end{array}$ \\
\hline CFS (M) & 207 & $3.03 \pm 1.7$ & $4.73 \mathrm{M}$ & (Shiferaw et al. 2003) \\
\hline NSPC & 149 & $2.75 \pm 1.7$ & $1.75 \mathrm{M}$ & (Shiferaw et al. 2003) \\
\hline CI (M) & 212 & $14.28 \pm 3.403$ & $15-18 \mathrm{M}$ & $\begin{array}{l}\text { (Shiferaw et al. 2003; Siyoum et al. 2016; } \\
\text { Yalew et al. 2011) }\end{array}$ \\
\hline Lactation length (M) & 235 & $11.54 \pm 3.418$ & & \\
\hline Daily milk yield in (L) & 250 & $12.35 \pm 6.697$ & & \\
\hline Calf mortality & 75 & $1.71 \pm 1.566$ & & \\
\hline
\end{tabular}

Description:; AFS= Age at first service AFC Age at 1st caving; CFS=Calving to first service, NSPC=No. of services per conception, $C I=$ Calving interval; $M=$ month

The mean AFS, AFC and CI were lower than previous reports. A 26 years retrospective analysis made by Yalew et al. (Yalew et al. 2011), a reproductive constraint in crossbred dairy cows under four different production systems in the central highlands of Ethiopia by Shiferaw et al. (Shiferaw et al. 2003), reproductive performances of Jersey dairy cattle maintained at Adeaberga dairy farm by Siyoum et al. (Siyoum et al. 2016) showed the mean AFS, AFC and CI to be 26-29 M, 35-41M and 15-18M, respectively. The difference might be attributed to the impact of training and large-scale dairy technology demonstration performed in the area and the interventions of various stakeholders on dairy feeding and nutrition, management and health, to better the reproductive and productive performance.

\subsection{Major reproductive problems encountered}

Among the selected 252 dairy cows, $102(40.5 \%)$ encountered reproductive health problem at least once in their production time. The major reproductive disorders recorded with high prevalence in the present study were mastitis 
(43.6\%), abortion (13.8\%), ROP (21.3\%) and dystocia (7.4\%). While Vaginal prolapses (1.6\%), repeated breeding $(3.25 \%)$ and anoestrus $(5.3 \%)$ were other reproductive health problems with a lower incidence rate (Table 4).

Table 4: Major reproductive problems observed in selected cows

\begin{tabular}{|l|l|l|l|}
\hline Question & Response category & No. & $\%$ \\
\hline \multirow{3}{*}{$\begin{array}{l}\text { Reproductive health problem } \\
\text { encountered }(\mathrm{n}=252)\end{array}$} & Yes & 102 & 40.5 \\
\cline { 2 - 4 } & No & 134 & 53.2 \\
\cline { 2 - 4 } & Not sure & 16 & 6.3 \\
\hline \multirow{3}{*}{$\begin{array}{l}\text { Major reproductive health problems } \\
\text { observed }(\mathrm{n}=94)\end{array}$} & Mastitis & 41 & 43.6 \\
\cline { 2 - 4 } & ROP & 20 & 21.3 \\
\cline { 2 - 4 } & Abortion and stillbirth & 13 & 13.8 \\
\cline { 2 - 4 } & Dystocia & 7 & 7.4 \\
\cline { 2 - 4 } & Anoestrus & 5 & 5.3 \\
\cline { 2 - 4 } & Uterine Prolapse & 5 & 5.3 \\
\cline { 2 - 4 } & Repeated Breeding & 3 & 3.2 \\
\hline Measures taken $(\mathrm{n}=94)$ & Animal Treated & 88 & 93.5 \\
\cline { 2 - 4 } & Not treated & 6 & 6.5 \\
\hline Response to treatment $(\mathrm{n}=86)$ & Good & 81 & 89.4 \\
\cline { 2 - 3 } & Poor & 10 & 11.6 \\
\hline
\end{tabular}

The prevalence of mastitis reported in this study is high as compared to the reports of Lema et al. (Lema et al. 2001) in central highlands of Ethiopia and Tolosa et al. (Tolosa, Netsere, and Habtamu 2021) in Bale with a morbidity rate of $19 \%$ and $20 \%$, respectively. The difference might be attributed to the breed of cows and the average milk yield of studied animals. Cows with high milk yield and high exotic blood level are prone to mastitis.

Retention of the placenta was the second-highest reproductive disorder observed in the current study. ROP is the most undetermined reproductive disorder in dairy farms. But the condition might contribute to lower milk yield, long calving interval, repeated service per conception and high risk of fatty liver (Han and Kim 2005; Rajala and Grohn 2000). ROP is mainly caused by a failure in hormonal regulation (Ibrahim 2018); the level of estrogen in a pregnant cow should reach peak, a week before parturition to produce strong motility in the uterus and to get rid of the fetal membranes after birth. To this effect, the body must favour estrogen synthesis by declining the level of progesterone. The process is induced by fetal cortisol via the production of the enzymes, 17 - hydroxylase and aromatase (Ibrahim 2018).

Anoestrus and repeated breedings were reported as a major cause of reproductive health problem in northern Ethiopia, Nazereth (Adama), central Ethiopia, Kombolcha, and around Assella, Hossana and fiche with a magnitude of $6.1 \%, 2.2 \%, 6.7 \%, 9.1 \%, 14.6 \%, 2.6 \%$ and $8.4 \%$, respectively (Abdella and Regassa 2013; Bekena, Ekman, and Kindhal 2011; Dawite and Ahmed 2013; Haile, Tsegaye, and Tesfaye 2014; Hunduma 2013; Micheal 2003; Tesfaye, Tirsit, and Yitagesu 2017). Moreover, a prolonged anoestrus of 47\% was also reported by Siyoum et al. (Siyoum et al. 2016) in Jersey breeds reared in Adea Berga dairy farm. A higher magnitude of repeat breeding was observed in Hawassa (Micheal 2003), Central Ethiopia (Abdella and Regassa 2013), Hossana (Haile et al. 2014) and around Fiche (Tesfaye et al. 2017).

The prevalence of abortion unveiled by the current study is high. Many authors report the impact of abortion on dairy reproductive performance in different parts of the country. A much higher $(28.9 \%)$ abortion rate was reported by Siyoum et al. (Siyoum et al. 2016), whereas Abunna et al. (Abunna et al. 2018) and Tolosa et al. (Tolosa et al. 2021) reported $8 \%$ and $4.1 \%$, abortion rate respectively, in different breeds and farm settings. The presence of abortion in a dairy farm extends the calving interval which largely affects the profit of the dairy farm. Abortion resulted from pathogenic microbial invasion may cause prolonged infertility or sterility. Abortion and stillbirth increase the rate of pregnancy wastage in the form of embryonic, fetal and newborn losses. Thus, it can be considered as an important farm animal reproductive constraint. Abortion can be caused by numerous factors including dam's physiology, reproduction capacity and diseases of bacterial, viral, protozoan and fungal origins. Abortion resulted from reproductive tract infections also pose a serious zoonotic risk (Parkinson, Noakes, and England 2001).

Uterine prolapse is another reproductive system problem observed in the current study. The condition is almost common in dairy animals and when it occurs it usually affects the cow by reducing the postpartum return to estrus, conception rate and calving interval in dairy cattle (Kumar and Yasotha 2015), which in turn affects the operation of the dairy farm. There is no definite cause for the problem even though it is mostly associated with milk fever (hypocalcemia), poor uterine tone, increased straining, the weight of the retained fetal membrane, tympany and excessive estrogen content in the feed (Hanie 2006; Jackson 2004; Kumar and Yasotha 2015). 


\subsection{Risk factors for reproductive health problem}

Reproductive problems observed more frequently in aged cows than young cows; in Good body condition than medium body condition cows; and in crossbreed cows than local breed cows (Table 5).

Table 5: the prevalence of reproductive health problems categorized in different variables

\begin{tabular}{|c|c|c|c|c|}
\hline \multirow{2}{*}{ Risk factors } & \multirow{2}{*}{ Category } & \multirow[t]{2}{*}{ Cows } & \multicolumn{2}{|c|}{ Affected cows } \\
\hline & & & $\mathbf{N}$ & $\%$ \\
\hline \multirow[t]{2}{*}{$\mathrm{BCS}$} & Good Body condition & \multirow{2}{*}{235} & 57 & 24.3 \\
\hline & Medium Body Condition & & 44 & 18.7 \\
\hline \multirow{2}{*}{ Age } & $0-5$ years & \multirow{2}{*}{198} & 28 & 14.1 \\
\hline & Above 5 Years & & 62 & 31.3 \\
\hline \multirow{2}{*}{ Parity } & $1-3$ calves & \multirow{2}{*}{234} & 77 & 32.9 \\
\hline & More than 3 calves & & 24 & 10.3 \\
\hline \multirow{2}{*}{ Age at maturity } & Less than 24 months & \multirow{2}{*}{174} & 65 & 37.4 \\
\hline & Above 24 months & & 10 & 5.7 \\
\hline \multirow{2}{*}{ Age at first calving } & Below 30 months & \multirow{2}{*}{181} & 64 & 35.4 \\
\hline & 30 months and above & & 15 & 8.3 \\
\hline \multirow{2}{*}{ Breed of Cow } & Local breed & \multirow{2}{*}{235} & 19 & 8.1 \\
\hline & Crossbreed & & 83 & 35.3 \\
\hline
\end{tabular}

The prevalence of reproductive problems showed significant difference with respect to the age of cows $(p=0.01)$, body condition $(\mathrm{p}=0.04)$ and breed of cow $(\mathrm{p}=0.04)$ (Table 6).

Table 6: Strength of association between reproductive health problems and associated risk factors

\begin{tabular}{|l|l|l|l|l|l|l|}
\hline Variables * rep problems & B & S.E. & Wald & Sig. & Exp (B) & $95 \%$ CI \\
\hline Age of Cow & .989 & .398 & 6.18 & .01 & 2.689 & $1.23-5.863$ \\
\hline Body condition & -.68 & .338 & 4.04 & .04 & .507 & $.261-.983$ \\
\hline Breed of cow & .914 & .438 & 4.35 & .04 & 2.495 & $1.05-5.889$ \\
\hline
\end{tabular}

However, the occurrence of reproductive problems was statistically insignificant with respect to parity, age at first calving, breeding method, farming system and age at maturity $(\mathrm{p}>0.05)$. The overall incidence of reproductive disorders in this study and the identified risk factors were also reported earlier (Tolosa et al. 2021). The presence of reproductive disorder of any kind exerts its negative effect on farms. Long calving interval and low conception rate in dairy cows may increase the risk of involuntary culling (Gröhn and Rajala-Schultz 2000).

\section{Conclusion and recommendation}

The current study showed major reproductive problems in the selected study area. The overall prevalence $(40.5 \%)$ noted in this study is relatively higher than various reports. Mastitis, abortion, ROP and dystocia were identified as the major reproductive problems of high magnitude. While Vaginal prolapses, repeated breeding and anoestrus occurs with a lower incidence rate. Breed of selected cow, age of cows and body condition were found to be a risk factor for observed reproductive problems. Therefore, a planned intervention comprising feeds and nutrition, breeding and health packages is required to reduce the occurrence of reproductive health problems in the area.

Most of the farms do not keep performance records like breeding, production and health records. These records apart from performance measurement can help to identify factors that may be associated with the observed reproductive problems, which in turn used to design and implement intervention options. Therefore, farmers should be advised and trained to keep performance recording.

The current study was based on a questionnaire survey with rapid clinical inspection thus lacks laboratory confirmation of the cases. It is also difficult to tell the exact reason behind the abortion, stillbirth and mastitis observed in the study. Therefore, exhaustive laboratory investigations are needed to identify infectious and noninfectious causes of reproductive health problems at a grass-root level.

Further studies are required to develop, evaluate and validate intervention and management methods across different management system to minimize the antepartum and postpartum reproductive problems.

\section{Reference}

Abdella, A., and F. Regassa. 2013. "The Major Prepartum and Postpartum Reproductive Problems of Dairy Cattle in Central Ethiopia." J of Vet. Med and Anim Health 5(4):118-123.

Abunna, Fufa, Blen Merid, Gebeyehu Goshu, Hika Waktole, and Gezahegn Mammo. 2018. “Assessment of Major Reproductive Health Problems, Their Effect on Reproductive Performances and Association with 
Brucellosis in Dairy Cows in Bishoftu." 14-20.

Bekena, M., T. Ekman, and H. Kindhal. 2011. "The Major Reproductive Health Problems in Small Holder Dairy Production in and around Nazareth Town, Central Ethiopia." J. Dairy Sci 71:2572-2583.

CSA. n.d. Agricultural Sample Survey, Vol. II: Report on Livestock and Livestock Characteristics (Private Peasant Holdings). Vol. II. Addis Ababa, Ethiopia.

Dawite, T., and S. Ahmed. 2013. "Reproductive Health Problems of Cows under Different Management Systems in Kombolcha, North East Ethiopia, Hawassa University, School of Veterinary Medicine, Hawassa, Ethiopia." Adva in Biological Res 7(3):104-108.

Gröhn, Y. T., and P. J. Rajala-Schultz. 2000. "Epidemiology of Reproductive Performance in Dairy Cows.” Animal Reproduction Science 60-61:605-14.

Haile, Adane, Yisehak Tsegaye, and Niguse Tesfaye. 2014. "Assessment of Major Reproductive Disorders of Dairy Cattle in Urban and per Urban Area of Hosanna, Southern Ethiopia." Animal and Veterinary Science 2(5):135-41.

Han, Y. K., and I. H. Kim. 2005. "Risk Factors for Retained Placenta and the Effect of Retained Placenta on the Occurrence of Postpartum Diseases and Subsequent Reproductive Performance in Dairy Cows." Journal of Veterinary Science 6:53-59.

Hanie, E. A. 2006. "Prolapse of the Vaginal and Uterus: Text Book of Large Animal Clinical Procedures for Veterinary Technicians." Elsevier text book:218-221.

Hunduma, D. 2013. "The Major Reproductive Disorders of Dairy Cows in and around Asella Town, Central Ethiopia." J. of Vet. Med. and Animal Health 5(4):113-117.

Ibrahim, Nuraddis. 2018. "A Review on Reproductive Health Problem in Dairy Cows in Ethiopia A Review on Reproductive Health Problem in Dairy Cows in Ethiopia." Canadian Journal of Scientific Research 6(1).

Jackson, P. G. G. 2004. Postparturient Problems in Large Animals. Hand book of veterinary obstetrics.2nd Ed., Elsevier Saunders. Pp.

Kumar, A. S., and A. Yasotha. 2015. "Correction and Management of Total Uterine Prolapse in a Crossbred Cow." Journal of Agriculture and Veterinary Sciences 8(1):14-16.

Lema, M., T. Kassa, and A. Tegegne. 2001. "Clinically Manifested Major Health Problems of Crossbred Dairy Herds in Urban and Periurban Production Systems in the Central Highlands of Ethiopia." Tropical Animal Health and Production 33(2):85-93.

Lobago, F., M. Bekana, H. Gustafsson, and H. Kindahl. 2006. "Reproductive Performances of Dairy Cows in Smallholder Production System in Selalle , Central Ethiopia." Tropical Animal Health and Production 38:333-42.

Micheal, K. 2003. "Major Clinical Reproductive Problem of Small Holder Dairy Cows in and around Hawassa." Addis Ababa University, Faculty of Veterinary Medicine.

Nakada, Ken. 2006. "How to Improve Reproductive Efficacy from Now in Japan? Find out the Factors of Late Lactation to Predict Postpartum Reproductive Diseases."Journal of Reproduction and Development 52(1):177-83.

Parkinson, T. J., D. E. Noakes, and G. C. W. England. 2001. "Veterinary Reproduction and Obstetrics.” $383-472$.

Rajala, P. J., and Y. T. Grohn. 2000. "Effects of Dystocia, Retained Placenta, and Metritis on Milk Yield in Dairy Cows." Journal of Dairy Science 81:3172-3181.

Rashid, M. n.d. "Reproductive Wastage in Cattle Due to Bovine Brucellosis." Pp. 270-272 in Proceedings of the Fourth National Livestock Improvement Conference. Ethiopia: Institute of Agricultural Research. Addis Ababa.

Shiferaw, Y., B. A. Tenhagen, M. Bekana, and T. Kassa. 2003. "Reproductive Performance of Crossbred Dairy Cows in Different Production Systems in the Central Highlands of Ethiopia." Tropical Animal Health and Production 35(6):551-61.

Shiferaw, Y., B. A. Tenhagen, M. Bekana, and T. Kassa. 2005. "Reproductive Disorders of Crossbred Dairy Cows in the Central Highlands of Ethiopia and Their Effect on Reproductive Performance." Tropical Animal Health and Production 37(5):427-41.

Sibhat, Berhanu, Gelagay Ayelet, Eystein Skjerve, and Endrias Z. Gebremedhin. 2018. "Bovine Herpesvirus-1 in Three Major Milk Sheds of Ethiopia: Serostatus and Association with Reproductive Disorders in Dairy Cattle." Preventive Veterinary Medicine 150:126-32.

Siyoum, Tamirat, Aster Yohannes, Yosef Shiferaw, Zerihun Asefa, and Melese Eshete. 2016. "Major Reproductive Disorders on Jersey Breed Dairy Cattle at Adea Berga Dairy Farm, West Shewa Zone, Oromia Region, Ethiopia." Ethiopian Veterinary Journal 20(1):91.

Tesfaye, Dufera, Kuma Tirsit, and Belachew Yitagesu. 2017. "Major Reproductive Disorder and Performances of Small Holder Dairy Farms in and around Fitche Town, North Shoazone of Oromia Regional State, Centeral Ethioipia." Journal of Reproduction and Infertility 8(1):10-17,.

Tolosa, Fedhiko, Misrak Netsere, and Yitbarek Habtamu. 2021. “Assessment of Major Reproductive Disorders in 
Dairy Cattle in and around Bale Robe, Oromia Regional State, Ethiopia.” Veterinary Medicine International 2021.

Town, Gondar. 2017. "Study on the Major Dairy Cows Reproductive Problems in and Around Gondar Town, Northwest Ethiopia.” Journal of Veterinary V Eterinary Science \& T Echnology 8(6).

Yalew, Berhanu, Fikre Lobago, and Gebeyehu Goshu. 2011. "Calf Survival and Reproductive Performance of Holstein - Friesian Cows in Central Ethiopia." Tropical Animal Health and Production 359-65.

Zemenu, Getnet, Haimanot Belete, and Wahid M. Ahmed. 2018. "Common Reproductive Disorders of Dairy Cattle and Their Prevalence in Ethiopia." Global Veterinaria 20(2):60-72. 